\title{
Fuzzy Sets, Fuzzy S-Open and S-Closed Mappings
}

\author{
B. Ahmad ${ }^{1,2}$ and Athar Kharal ${ }^{1}$ \\ ${ }^{1}$ Centre for Advanced Studies in Pure and Applied Mathematics, Bahauddin Zakariya University, Multan 60800, Pakistan \\ ${ }^{2}$ Department of Mathematics, King Abdul Aziz University, P.O. Box 80203, Jeddah 21589, Saudi Arabia
}

Correspondence should be addressed to Athar Kharal, atharkharal@gmail.com

Received 10 October 2008; Revised 28 February 2009; Accepted 13 April 2009

Recommended by Zeki Ayag

Several properties of fuzzy semiclosure and fuzzy semi-interior of fuzzy sets defined by Yalvac (1988), have been established and supported by counterexamples. We also study the characterizations and properties of fuzzy semi-open and fuzzy semi-closed sets. Moreover, we define fuzzy s-open and fuzzy s-closed mappings and give some interesting characterizations.

Copyright (C) 2009 B. Ahmad and A. Kharal. This is an open access article distributed under the Creative Commons Attribution License, which permits unrestricted use, distribution, and reproduction in any medium, provided the original work is properly cited.

\section{Introduction}

The concept of fuzzy set was introduced by Zadeh in his classical paper [1]. This concept provides a natural foundation for treating mathematically the fuzzy phenomena, which exist pervasively in our real world, and for building new branches of fuzzy mathematics. In the area of Fuzzy Topology, introduced by Chang [2], much attention has been paid to generalize the basic concepts of General Topology in fuzzy setting and thus a modern theory of Fuzzy Topology has been developed.

In recent years, Fuzzy Topology has been found to be very useful in solving many practical problems. Du et al. [3] fuzzified the very successful 9-intersection Egenhofer model $[4,5]$ for depicting topological relations in Geographic Information Systems (GIS) query. In [6, 7], El Naschie showed that the notion of Fuzzy Topology might be relevant to quantum particle physics and quantum gravity in connection with string theory and $e^{\infty}$ theory. Tang [8] used a slightly changed version of Chang's fuzzy topological space to model spatial objects for GIS databases and Structured Query Language (SQL) for GIS.

Levine [9] introduced the concepts of semi-open sets and semicontinuous mappings in topological spaces. Interestingly, his work found applications in the field of Digital Topology [10]. For example, it was found that the digital line is a $T_{1 / 2}$-space [11], which is a weaker separation axiom based upon semi-open sets. Fuzzy Digital Topology [12] was introduced by A. Rosenfeld, which demonstrated the need for the fuzzification of weaker forms of notions of
Classical Topology. Azad [13] carried out this fuzzification in 1981, and presented some general properties of fuzzy spaces. Several properties of fuzzy semi-open (resp., fuzzy semi-closed), fuzzy regular open (resp., closed) sets have been discussed. Moreover he defined fuzzy semicontinuous (resp., semi-open and semi-closed) functions and studied the properties of fuzzy semicontinuous function in product related spaces. Finally, he defined and characterized fuzzy almost continuous mappings. For related subsequent work in this direction, we refer to [14-27].

In this paper, our aim is to further contribute to the study of fuzzy semi-open and fuzzy semi-closed sets defined by Yalvac [26] by establishing several important fundamental identities and inequalities supported by counterexamples. Cameron and Woods [28] introduced the concepts of s-continuous mappings and s-open mappings. They investigated the properties of these mappings and their relationships to properties of semi-open sets. Khan and Ahmad [29] further worked on the characterizations and properties of s-continuous, s-open and s-closed mappings. We fuzzify the findings of $[28,29]$. We define fuzzy s-open and fuzzy s-closed mappings and establish some interesting characterizations of these mappings.

\section{Preliminaries}

In order to make this paper self-contained, we briefly recall certain definitions and results; for those not described, we refer to $[1,2,13,26]$. 
Let $X=\{x\}$ be a space of points (objects), with a generic element $x$. A fuzzy set $\lambda$ in $X$ is characterized by membership function $\lambda(x)$ from $X$ to the unit interval $[0,1]$.

The symbol $\Phi$ denotes the empty fuzzy set defined as $\mu_{\Phi}(x)=0$, for all $x \in X$. For $X$, the membership function is defined as $\mu_{X}(x)=1$, for all $x \in X$.

Definition 1 (see [2]). Let $f: X \rightarrow Y$ be a mapping. Let $\beta$ be a fuzzy set in $Y$ with membership function $\beta(y)$. Then the inverse of $\beta$, written as $f^{-1}(\beta)$, is a fuzzy set in $X$ whose membership function is defined by

$$
f^{-1}(\beta)(x)=\beta(f(x)), \quad \forall x \in X .
$$

Conversely, let $\lambda$ be a fuzzy set in $X$ with membership function $\lambda(x)$. The image of $\lambda$, written as $f(\lambda)$, is a fuzzy set in $Y$ whose membership function is given by

$$
f(\lambda)(y)= \begin{cases}\sup _{x \in f^{-1}(y)}\{\lambda(x)\}, & \text { if } f^{-1}(y) \text { is nonempty } \\ 0, & \text { otherwise }\end{cases}
$$

for all $y \in Y$.

Definition 2 (see [2]). A fuzzy topology is a family $\tau$ of fuzzy sets in $X$, which satisfies the following conditions:

(1) $\Phi, X \in \tau$;

(2) If $\lambda, \mu \in \tau$, then $\lambda \wedge \mu \in \tau$;

(3) If $\lambda_{i} \in \tau$ for each $i \in I$, then $\vee_{i} \lambda_{i} \in \tau$.

$\tau$ is called a fuzzy topology for $X$, and the pair $(X, \tau)$ is an fts. Every member of $\tau$ is called $\tau$-open fuzzy set (or simply an open fuzzy set). A fuzzy set is $\tau$-closed if and only if its complement is $\tau$-open.

As in general topology, the indiscrete fuzzy topology contains only $\Phi$ and $X$, while the discrete fuzzy topology contains all fuzzy sets.

\section{Fuzzy Semi-Open and Fuzzy Semi-Closed Sets}

Definition 3 (see [13]). Let $\lambda$ be a fuzzy set in an $\mathrm{fts}(X, \tau)$. Then $\lambda$ is called a fuzzy semi-open set of $X$, if there exists a $\nu \in \tau$ such that $\nu \leq \lambda \leq \mathrm{Cl} \nu$. A fuzzy set $\mu$ is fuzzy semiclosed if and only if its complement $\mu^{c}$ is fuzzy semi-open. The class of all fuzzy semi-open (resp., fuzzy semi-closed) sets in $X$ is denoted by $\mathrm{FSO}(X)$ (resp., $\operatorname{FSC}(X)$ ).

Definition 4 (see [26]). Let $\lambda$ be a fuzzy set in an $\mathrm{fts} X$. Then semi-closure (briefly $\mathrm{sCl}$ ) and semi-interior (briefly sInt) of $\lambda$ are defined as

$$
\begin{aligned}
\operatorname{sCl} \lambda & =\wedge\{\beta \mid \lambda \leq \beta, \beta \text { fuzzy semi-closed }\}, \\
\operatorname{sint} \lambda & =\vee\{\beta \mid \beta \leq \lambda, \beta \text { fuzzy semi-open }\},
\end{aligned}
$$

and are called the fuzzy semi-closure of $\lambda$ and fuzzy semiinterior of $\lambda$, respectively.
It is immediate that

(1) $\mathrm{sCl} \lambda \geq \lambda$ and $\operatorname{sInt} \lambda \leq \lambda$;

(2) $\lambda \leq \mu \Rightarrow \operatorname{sCl} \lambda \leq \mathrm{sCl} \mu, \operatorname{sInt} \lambda \leq \operatorname{sInt} \mu$.

It is known [13] that a fuzzy set $\lambda$ in an $\mathrm{fts} X$ is

(1) fuzzy semi-closed if and only if $\operatorname{IntCl} \lambda \leq \lambda$ (resp., $\mathrm{s} \mathrm{Cl} \lambda=\lambda)$

(2) fuzzy semi-open if and only if $\lambda \leq \operatorname{ClInt} \lambda$ (resp., $\operatorname{sint} \lambda=\lambda$ ).

The following are characterizations of fuzzy semi-closed sets, the proof of Theorem 1 is straightforward.

Theorem 1. A fuzzy set $\lambda$ is fuzzy semi-closed if and only if there exists a fuzzy closed set $\psi$ such that Int $\psi \leq \lambda \leq \psi$.

Theorem 2. For a fuzzy set $\lambda$ in an fts $X, \lambda$ is fuzzy semi-closed if and only if sIntsCl $\lambda \leq \lambda$.

Proof. $(\Rightarrow)$ If $\lambda$ is a fuzzy semi-closed set, that is, $\lambda=\operatorname{sCl} \lambda$, then $\operatorname{sintsCl} \lambda=\operatorname{sInt} \lambda \leq \lambda$.

$(\Leftrightarrow)$ Suppose $\operatorname{sint}(\operatorname{sCl} \lambda) \leq \lambda$. Since $\operatorname{sCl} \lambda$ is fuzzy semiclosed, so there exists a closed set $\psi$ such that Int $\psi \leq \mathrm{sCl} \lambda \leq$ $\psi$. Thus Int $\psi \leq \operatorname{sIntsCl} \lambda \leq \lambda \leq \operatorname{sCl} \lambda \leq \psi$ or Int $\psi \leq \lambda \leq \psi$. Hence $\lambda$ is fuzzy semi-closed and $\lambda=\operatorname{sCl} \lambda$.

Remark 1. It is easily seen that

(1) if $\lambda$ is fuzzy semi-open (resp., fuzzy semi-closed), then $\operatorname{Int} \lambda, \operatorname{sint} \lambda, \mathrm{sCl} \lambda$, and $\mathrm{Cl} \lambda$ are fuzzy semi-open (resp., fuzzy semi-closed);

(2) a nonvoid nowhere dense fuzzy set $\lambda$ is fuzzy semiclosed and not fuzzy semi-open.

The converse of Remark 1(2) is, in general, not true as is shown by following.

Example 1. Let $X=\{a, b, c\}$ be a set and $I=\{0, .3, .5, .7,1\}$ be the lattice of membership grades for fuzzy sets in $X$. Let $\mu=\left\{a_{.7}, b_{0}, c_{1}\right\}, \nu=\left\{a_{.7}, b_{.5}, c_{.3}\right\}$, and $\omega=\left\{a_{.5}, b_{.5}, c_{.5}\right\}$ be fuzzy sets on $X$, and $\tau$ the fuzzy topology generated by $\mu, \nu$, and $\omega$. Then $\tau=\left\{\Phi, \mu, \nu, \omega,\left\{a_{.5}, b_{0}, c_{.5}\right\},\left\{a_{.5}, b_{.5}, c_{.3}\right\}\right.$, $\left.\left\{a_{.7}, b_{0}, c_{.3}\right\},\left\{a_{.7}, b_{0}, c_{.5}\right\},\left\{a_{.7}, b_{.5}, c_{.5}\right\},\left\{a_{.7}, b_{.5}, c_{1}\right\}, X\right\}$.

Calculations give that fuzzy set $\omega$ is both fuzzy semi-closed and fuzzy semi-open but $\operatorname{IntCl} \omega=\omega$.

Theorem 3. For fuzzy sets $\lambda$ and $\mu$ in an fts $X$, one has

(1) $\sin t(\lambda \vee \mu) \geq \sin t \lambda \vee \operatorname{sint} \mu$;

(2) $\sin t(\lambda \wedge \mu)=\sin t \lambda \wedge \sin t \mu$;

(3) $s C l(\lambda \vee \mu)=s C l \lambda \vee s C l \mu$;

(4) $s C l(\lambda \wedge \mu) \leq s C l \lambda \wedge s C l \mu$.

Proof. (1) $\operatorname{sint} \lambda$ and $\operatorname{sint} \mu$ are both fuzzy semi-open . $\lambda \leq$ $\lambda \vee \mu, \mu \leq \lambda \vee \mu$ imply $\operatorname{sint} \lambda \leq \operatorname{sint}(\lambda \vee \mu)$ and $\operatorname{sint} \mu \leq$ $\operatorname{sInt}(\lambda \vee \mu)$. Combining, $\operatorname{sint} \lambda \vee \operatorname{sint} \mu \leq \operatorname{sInt}(\lambda \vee \mu)$ or

$$
\operatorname{sint}(\lambda \vee \mu) \geq \operatorname{sint} \lambda \bigvee \operatorname{sint} \mu \text {. }
$$


(2) $\lambda \wedge \mu \leq \lambda$ and $\lambda \wedge \mu \leq \mu$ imply $\operatorname{sint}(\lambda \wedge \mu) \leq \operatorname{sint} \lambda \wedge$ $\operatorname{sInt} \mu$. Conversely $\operatorname{sInt} \lambda \leq \lambda$ and $\operatorname{sint} \mu \leq \mu$ imply $\operatorname{sint} \lambda \wedge$ $\operatorname{sInt} \mu \leq \lambda \wedge \mu$ and $\operatorname{sint} \lambda \wedge \operatorname{sInt} \mu$ is fuzzy semi-open. But $\operatorname{sInt}(\lambda \wedge \mu)$ is the largest fuzzy semi-open set such that $\operatorname{sint}(\lambda \wedge$ $\mu) \leq \lambda \wedge \mu$, hence $\operatorname{sInt} \lambda \wedge \operatorname{sInt} \mu \leq \operatorname{sint}(\lambda \wedge \mu)$. This gives the equality.

(3) and (4) follow easily from (2).

The inequalities (1) and (4) of Theorem 3, are in general irreversible, as is shown by following.

Example 2. Let $X=\{a, b\}$ be a set and $I=\{0, .5,1\}$ be the lattice of membership grades for fuzzy sets on $X$. Let $\mu=$ $\left\{a_{.5}, b_{1}\right\}, \nu=\left\{a_{.0}, b_{1}\right\}$, and $\omega=\left\{a_{1}, b_{.5}\right\}$ be fuzzy sets on $X$, and $\tau$ the fuzzy topology generated by $\mu, \nu$, and $\omega$. Then

$$
\tau=\left\{\Phi, \mu, \nu, \omega,\left\{a_{.5}, b_{.5}\right\},\left\{a_{0}, b_{.5}\right\}, X\right\} .
$$

We choose fuzzy sets $\alpha=\left\{a_{.5}, b_{0}\right\}, \beta=\left\{a_{0}, b_{.5}\right\}, \gamma=$ $\left\{a_{.5}, b_{1}\right\}$ and $\delta=\left\{a_{1}, b_{.5}\right\}$. Then calculations give that

$$
\begin{aligned}
\operatorname{sint}(\alpha \vee \beta) & =\left\{a_{.5}, b_{.5}\right\} \nless\left\{a_{0}, b_{.5}\right\}=\operatorname{sint} \alpha \vee \operatorname{sInt} \beta, \\
\operatorname{sCl} \gamma \wedge \operatorname{sCl} \delta & =\left\{a_{1}, b_{.5}\right\} \nless\left\{a_{.5}, b_{.5}\right\}=\operatorname{sCl}(\gamma \wedge \delta) .
\end{aligned}
$$

It is known [30] that for a fuzzy set $\lambda$ in an $\mathrm{fts} X$, we have

(1) $\mathrm{ClsCl} \lambda=\mathrm{Cl} \lambda$;

(2) $\operatorname{IntCl} \lambda \leq \mathrm{sCl} \lambda$.

We use this and Theorem 1, and prove the following.

Theorem 4. Let $\lambda$ be a fuzzy set in an fts X. Then one has the following:
(1) $s \operatorname{Cls} C l \lambda=s C l \lambda(\operatorname{sintsInt} \lambda=s \operatorname{Int} \lambda)$;

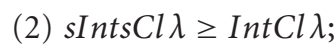
(3) IntsIntsCl $\lambda=\operatorname{IntCl} \lambda$;

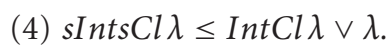

Proof. (1) By the fact that $\mathrm{sCl} \lambda$ is fuzzy semi-closed and that $\lambda$ is fuzzy semi-closed if and only if $\mathrm{sCl} \lambda=\lambda$, it follows immediately.

(2) Since, $\operatorname{IntCl} \lambda \leq \operatorname{sCl} \lambda$, so that $\operatorname{IntCl} \lambda \leq \operatorname{sintsCl} \lambda$, since all fuzzy open sets are fuzzy semi-open.

(3) By (2), IntCl $\lambda \leq \operatorname{sintsCl} \lambda$, so that $\operatorname{IntCl} \lambda \leq$ IntsIntsCl $\lambda$. Also $\mathrm{sCl} \lambda \leq \mathrm{Cl} \lambda$, so that $\operatorname{sints} \mathrm{Cl} \lambda \leq \mathrm{Cl} \lambda$ and IntsIntsCl $\lambda \leq \operatorname{IntCl} \lambda$. Consequently, we get (3).

(4) Now $\operatorname{IntCl} \lambda \leq \operatorname{IntCl} \lambda \vee \lambda \leq \mathrm{Cl} \lambda$ so by Theorem 1 , $\operatorname{IntCl} \lambda \vee \lambda$ is fuzzy semi-closed. Also $\lambda \leq \operatorname{IntCl} \lambda \vee \lambda$. Since $\mathrm{sCl} \lambda$ is the smallest fuzzy semi-closed set with $\lambda \leq \mathrm{sCl} \lambda$, therefore, $\mathrm{sCl} \lambda \leq \operatorname{IntCl} \lambda \vee \lambda$. Which implies $\operatorname{sInts} \mathrm{Cl} \lambda \leq$ $\mathrm{sCl} \lambda \leq \operatorname{IntCl} \lambda \vee \lambda$ or $\operatorname{sints} \mathrm{Cl} \lambda \leq \operatorname{IntCl} \lambda \vee \lambda$.

The inequalites (2) and (4) of Theorem 4 may, in general, not be reversible as is shown in the following.

Example 3. Let $X=\{a, b, c\}$ be a set and $I=\{0, .3, .5, .7,1\}$ be the lattice of membership grades for fuzzy sets on $X$. Let $\mu=\left\{a_{.5}, b_{1}, c_{3}\right\}, \nu=\left\{a_{0}, b_{.5}, c_{1}\right\}$, and $\omega=\left\{a_{.3}, b_{.7}, c_{.5}\right\}$ be fuzzy sets on $X$, and $\tau$ the fuzzy topology generated by $\mu, \nu$, and $\omega$. Then $\tau=\left\{\Phi, \mu, \nu, \omega,\left\{a_{0}, b_{.5}, c_{.5}\right\},\left\{a_{0}, b_{.5}, c_{.3}\right\}\right.$, $\left.\left\{a_{3.3}, b_{.7}, c_{.3}\right\},\left\{a_{.5}, b_{1}, c_{.5}\right\},\left\{a_{.3}, b_{.7}, c_{1}\right\},\left\{a_{.5}, b_{1}, c_{1}\right\}, X\right\}$.

We choose fuzzy sets $\lambda=\left\{a_{.7}, b_{.5}, c_{.5}\right\}$ and $\psi=$ $\left\{a_{0}, b_{0}, c_{.5}\right\}$, then calculations give that

$$
\begin{aligned}
\operatorname{sints} \mathrm{Cl} \lambda & =\left\{a_{.7}, b_{.5}, c_{.5}\right\} \nless\left\{a_{0}, b_{.5}, c_{.5}\right\}=\operatorname{IntCl} \lambda ; \\
\operatorname{IntCl} \psi \vee \psi & =\left\{a_{0}, b_{0}, c_{.5}\right\} \nless\left\{a_{0}, b_{0}, c_{0}\right\}=\operatorname{sintsCl} \psi .
\end{aligned}
$$

Theorem 5. For any fuzzy set $\lambda$ in an fts $X$, we have

(1) $(\sin t \lambda)^{c}=s \operatorname{Cl}\left(\lambda^{c}\right)$,

(2) $(s C l \lambda)^{c}=\operatorname{sint}\left(\lambda^{c}\right)$.

Proof. (1)

$$
\begin{aligned}
(\operatorname{sInt} \lambda)^{c} & =1-\operatorname{sInt} \lambda \\
& =1-\vee\{\mu \mid \mu \in \operatorname{FSO}(X) \text { and } \mu \leq \lambda\} \\
& =\wedge\{1-\mu \mid \mu \in \operatorname{FSO}(X) \text { and } \mu \leq \lambda\} \\
& =\wedge\left\{\psi \mid \psi^{c} \in \operatorname{FSO}(X) \text { and } \psi \geq \lambda^{c}\right\}, \\
& \quad \text { where } \psi=1-\mu
\end{aligned}
$$$$
=\operatorname{sCl}\left(\lambda^{c}\right) .
$$

(2) Similar to (1).

\section{Fuzzy S-Open and Fuzzy S-Closed Mappings}

First, we define

Definition 5. A function $f: X \rightarrow Y$ is said to be fuzzy sopen (resp., fuzzy s-closed) if the image of every fuzzy semiopen (resp., fuzzy semi-closed) set is fuzzy open (resp., fuzzy closed).

Obviously a fuzzy s-open function is fuzzy open.

Definition 6 (see [31]). A fuzzy point $e$ is called a boundary point of a fuzzy set $\lambda$ if and only if $e \in \mathrm{Cl} \lambda \wedge \mathrm{Cl} \lambda^{c}$. The union of all the boundary points of $\lambda$ is called a boundary of $\lambda$, denoted by $\mathrm{Bd} \lambda$. It is clear that

$$
\operatorname{Bd} \lambda=\mathrm{Cl} \lambda \wedge \mathrm{Cl} \lambda^{c} .
$$

Next, we define

Definition 7. Semiboundary (briefly sBd) of a fuzzy set $\lambda$ in an $\mathrm{fts} X$ is defined as

$$
\operatorname{sBd} \lambda=\operatorname{sCl} \lambda \wedge \mathrm{sCl} \lambda^{c} .
$$

In the following, we characterize fuzzy s-open mappings in terms of sInt, $\mathrm{sCl}$, and $\mathrm{sBd}$.

Theorem 6. For a function $f: X \rightarrow Y$, a fuzzy set $\alpha$ in an fts $X$ and a fuzzy set $\beta$ in an fts $Y$, then the following are equivalent: 
(1) $f$ is fuzzy s-open;

(2) $f(\operatorname{sint} \alpha) \leq \operatorname{Int} f(\alpha)$;

(3) $\operatorname{sint} f^{-1}(\beta) \leq f^{-1}(\operatorname{Int} \beta)$;

(4) $f^{-1}(C l \beta) \leq s C l\left(f^{-1}(\beta)\right)$;

(5) $f^{-1}(B d(\beta)) \leq s B d\left(f^{-1}(\beta)\right)$.

Proof. (1) $\Rightarrow(2)$ obviously $f(\operatorname{sint} \alpha) \leq f(\alpha) . f$ is fuzzy s-open gives $f(\operatorname{sint} \alpha)$ that is fuzzy open in $Y$. But Int $f(\alpha)$ is the largest fuzzy open set such that Int $f(\alpha) \leq f(\alpha)$. Therefore $f(\operatorname{sint} \alpha) \leq \operatorname{Int} f(\alpha)$, for any fuzzy set $\alpha$ in $X$. This gives (2).

(2) $\Rightarrow(3)$ For any fuzzy set $\beta$ in $Y, f^{-1}(\beta)=\alpha$ is a fuzzy set in $X$. Then by (2)

$$
f\left(\operatorname{sint} f^{-1}(\beta)\right) \leq \operatorname{Int}\left(f\left(f^{-1}(\beta)\right) \leq \operatorname{Int}(\beta),\right.
$$

or $f\left(\operatorname{sint} f^{-1}(\beta)\right) \leq \operatorname{Int} \beta$ or $\operatorname{sInt} f^{-1}(\beta) \leq$ $f^{-1} f\left(\operatorname{sint} f^{-1}(\beta)\right) \leq f^{-1}(\operatorname{Int} \beta)$ or $\operatorname{sint} f^{-1}(\beta) \leq f^{-1}(\operatorname{Int} \beta)$. This gives (3).

(3) $\Rightarrow(4)$ By (3), we have

$$
\begin{aligned}
\operatorname{sint} f^{-1}(\beta) & \leq f^{-1}(\operatorname{Int} \beta) \\
\left(f^{-1}(\operatorname{Int} \beta)\right)^{c} & \leq\left(\operatorname{sint} f^{-1}(\beta)\right)^{c} \\
& =\operatorname{sCl}\left(f^{-1}(\beta)\right)^{c} \quad(\text { by Theorem } 5(1)),
\end{aligned}
$$

or $\left(f^{-1}(\operatorname{Int} \beta)\right)^{c} \leq \operatorname{sCl}\left(f^{-1}(\beta)\right)^{c}$ or $f^{-1}\left(\mathrm{Cl} \beta^{c}\right) \leq \operatorname{sCl} f^{-1}\left(\beta^{c}\right)$ or $f^{-1}(\mathrm{Cl} \psi) \leq \operatorname{sCl} f^{-1}(\psi)$ where $\psi=\beta^{c}$, a fuzzy set in $Y$. This gives (4).

$(4) \Rightarrow(5)$ For a fuzzy set $\beta$ in $Y, \mathrm{Bd} \beta=\mathrm{Cl} \beta \wedge \mathrm{Cl}\left(\beta^{c}\right)$ is a fuzzy closed set in $Y$. Now $f^{-1}(\operatorname{Bd} \beta)=f^{-1}(\mathrm{Cl} \beta) \wedge$ $f^{-1}\left(\mathrm{Cl} \beta^{c}\right)$. Using (4) we have

$$
f^{-1}(\operatorname{Bd} \beta) \leq \operatorname{sCl}\left(f^{-1}(\beta) \wedge \operatorname{sCl}\left(f^{-1}\left(\beta^{c}\right)\right)\right.
$$

or

$$
f^{-1}(\operatorname{Bd} \beta) \leq \operatorname{sCl} f^{-1}(\beta) \wedge \operatorname{sCl}\left(f^{-1}(\beta)\right)^{c}=\operatorname{sBd} f^{-1}(\beta) .
$$

This gives (5).

In the following, we give characterizations of fuzzy sclosed mappings as follows.

Theorem 7. A function $f: X \rightarrow Y$ is fuzzy s-closed if and only if $C l f(\lambda) \leq f(s C l \lambda)$, for each fuzzy set $\lambda$ in an $f$ ts $X$.

Proof. $(\Rightarrow)$ Obviously $f(\lambda) \leq f(\mathrm{sCl} \lambda) \cdot f(\mathrm{sCl} \lambda)$ is fuzzy closed, since $f$ is fuzzy s-closed. But $\mathrm{Cl} f(\lambda)$ is the smallest fuzzy closed set with $f(\lambda) \leq \operatorname{Cl} f(\lambda)$. Therefore $\mathrm{Cl} f(\lambda) \leq$ $f(\mathrm{sCl} \lambda)$.

$(\Leftarrow)$ Let $\lambda \in \operatorname{FSC}(X)$. We show that $f(\lambda)$ is fuzzy closed. By hypothesis, $\mathrm{Cl} f(\lambda) \leq f(\operatorname{sCl} \lambda)=f(\lambda)$ or $\mathrm{Cl} f(\lambda) \leq f(\lambda)$. This proves that $f(\lambda)$ is fuzzy closed.

Theorem 8. If a function $f: X \rightarrow Y$ is fuzzy s-closed then for each fuzzy set $\beta$ in an fts $Y$ and each fuzzy semi-open set $\mu$ in an fts $X$ with $\mu \geq f^{-1}(\beta)$, there exists a fuzzy open set $\nu$ in $Y$ with $\nu \geq \beta$ such that $f^{-1}(\nu) \leq \mu$.
Proof. Let $\mu$ be an arbitrary fuzzy semi-open set in $X$ with $\mu \geq$ $f^{-1}(\beta)$, where $\beta$ is a fuzzy set in $Y$. Clearly $\left(f\left(\mu^{c}\right)\right)^{c}=\nu$ (say) is fuzzy open in $Y$. Since $f^{-1}(\beta) \leq \mu$, then straightforward calculations give that $\beta \leq \nu$. Moreover, we have

$$
\begin{aligned}
& f^{-1}(\nu)=f^{-1}\left(f\left(\mu^{c}\right)\right)^{c} \\
& =\left(f^{-1} f\left(\mu^{c}\right)\right)^{c} \leq \mu \\
& \text { or } f^{-1}(\nu) \leq \mu \text {. }
\end{aligned}
$$

Theorem 9. Let $f: X \rightarrow Y$ be a surjective function from an fts $X$ to an fts $Y$. If for each fuzzy set $\beta$ in $Y$ and each fuzzy semi-open set $\mu$ in $X$ with $\mu \geq f^{-1}(\beta)$, there exists a fuzzy open set $v$ in $Y$ with $v \geq \beta$ such that $f^{-1}(\nu) \leq \mu$, then $f$ is s-closed.

Proof. Let $\psi$ be an arbitrary fuzzy semi-closed set in $X$ and $y \in(f(\psi))^{c}$. Then

$$
f^{-1}(y) \leq f^{-1}(f(\psi))^{c}=\left(f^{-1} f(\psi)\right)^{c} \leq \psi^{c}
$$

or $f^{-1}(y) \leq \psi^{c}$. Since $\psi^{c}$ is fuzzy semi-open, therefore there exists a fuzzy open set $v_{y}$ with $y \in v_{y}$ such that $f^{-1}\left(v_{y}\right) \leq$ $\psi^{c}$. Since $f$ is surjective, we have $y \in \nu_{y} \leq(f(\psi))^{c}$. Thus $(f(\psi))^{c}=\vee\left\{\nu_{y} \mid y \in(f(\psi))^{c}\right\}$ is fuzzy open in $Y$ or $f(\psi)$ is fuzzy closed in $Y$. This proves that $f$ is s-closed.

Combining Theorems 8 and 9, we have the following.

Theorem 10. A surjective function $f: X \rightarrow Y$ is fuzzy sclosed if and only if for each fuzzy set $\beta$ in $Y$ and each fuzzy semi-open set $\mu$ in $X$ with $\mu \geq f^{-1}(\beta)$, there exists a fuzzy open set $v$ in $Y$ with $\nu \geq \beta$ such that $f^{-1}(\nu) \leq \mu$.

\section{References}

[1] L. A. Zadeh, "Fuzzy sets," Information and Computation, vol. 8, pp. 338-353, 1965.

[2] C. L. Chang, "Fuzzy topological spaces," Journal of Mathematical Analysis and Applications, vol. 24, pp. 182-190, 1968.

[3] S. Du, Q. Qin, Q. Wang, and B. Li, "Fuzzy description of topological relations I: a unified fuzzy 9-intersection model," in Proceedings of the 1st International Conference on Advances in Natural Computation (ICNC '05), vol. 3612 of Lecture Notes in Computer Science, pp. 1261-1273, Changsha, China, August 2005.

[4] M. J. Egenhofer and R. D. Franzosa, "Point-set topological spatial relations," International Journal of Geographical Information Systems, vol. 5, no. 2, pp. 161-174, 1991.

[5] M. J. Egenhofer and J. Herring, "Categorizing binary topological relations between regions, lines and points in geographic databases," Tech. Rep., Department of Surveying Engineering, University of Maine, Orono, Me, USA, 1991.

[6] M. S. El Naschie, "On the uncertainty of Cantorian geometry and the two-slit experiment," Chaos, Solitons \& Fractals, vol. 9, no. 3, pp. 517-529, 1998.

[7] M. S. El Naschie, "On the certification of heterotic strings, M theory and $e^{\infty}$ theory," Chaos, Solitons \& Fractals, pp. 2397$2408,2000$. 
[8] X. Tang, Spatial object modeling in fuzzy topological spaces with applications to land cover change in China, Ph. D. dissertation, University of Twente, Enschede, The Netherlands, 2004, ITC Dissertation no. 108.

[9] N. Levine, "Semi-open sets and semi-continuity in topological spaces," The American Mathematical Monthly, vol. 70, pp. 3641, 1963.

[10] A. Rosenfeld, "Digital topology," The American Mathematical Monthly, vol. 86, no. 8, pp. 621-630, 1979.

[11] J. Cao, M. Ganster, and I. Reilly, "Submaximality, extremal disconnectedness and generalized closed sets," Houston Journal of Mathematics, vol. 24, no. 4, pp. 681-688, 1998.

[12] A. Rosenfeld, "Fuzzy digital topology," Information and Control, vol. 40, no. 1, pp. 76-87, 1979.

[13] K. K. Azad, "On fuzzy semicontinuity, fuzzy almost continuity and fuzzy weakly continuity," Journal of Mathematical Analysis and Applications, vol. 82, no. 1, pp. 14-32, 1981.

[14] S. E. Abbas, "Fuzzy super irresolute functions," International Journal of Mathematics and Mathematical Sciences, no. 42, pp. 2689-2700, 2003.

[15] B. Ahmad and M. A. Kharal, "On some fuzzy mappings," Journal of Fuzzy Mathematics, vol. 16, no. 2, pp. 341-349, 2008.

[16] M. Athar and B. Ahmad, "Fuzzy boundary and fuzzy semiboundary," Advances in Fuzzy Systems, vol. 2008, Article ID 586893, 9 pages, 2008.

[17] B. Ahmad and M. Athar, "Fuzzy almost continuous functions," International Journal of Contemporary Mathematical Sciences, vol. 3, no. 33-36, pp. 1665-1677, 2008.

[18] M. Caldas, G. Navalagi, and R. Saraf, "On fuzzy weakly semiopen functions," Proyecciones, vol. 21, no. 1, pp. 51-63, 2002.

[19] M. Caldas, G. Navalagi, and R. Saraf, "Weakly $\theta$-closed functions between fuzzy topological spaces," Matematichki Vesnik, vol. 54, no. 1-2, pp. 13-20, 2002.

[20] M. C. Cueva and R. K. Saraf, "Preserving fuzzy sg-closed sets," Proyecciones, vol. 20, no. 2, pp. 127-138, 2001.

[21] D. N. Georgiou and B. K. Papadopoulos, "On fuzzy $\theta$ convergences," Fuzzy Sets and Systems, vol. 116, no. 3, pp. 385399, 2000.

[22] B. Ghosh, "Semi-continuous and semi-closed mappings and semi-connectedness in fuzzy setting," Fuzzy Sets and Systems, vol. 35, no. 3, pp. 345-355, 1990.

[23] I. M. Hanafy, "Fuzzy $\beta$-compactness and fuzzy $\beta$-closed spaces," Turkish Journal of Mathematics, vol. 28, no. 3, pp. 281293, 2004.

[24] S. J. Lee and E. P. Lee, "Fuzzy $r$-continuous and fuzzy $r$ semicontinuous maps," International Journal of Mathematics and Mathematical Sciences, vol. 27, no. 1, pp. 53-63, 2001.

[25] M. A. Kharal and B. Ahmad, "On some fuzzy mappings II," to appear in Journal of Fuzzy Mathematics.

[26] T. H. Yalvac, "Semi-interior and semiclosure of a fuzzy set," Journal of Mathematical Analysis and Applications, vol. 132, no. 2, pp. 356-364, 1988.

[27] A. M. Zahran, "Regularly open sets and a good extension on fuzzy topological spaces," Fuzzy Sets and Systems, vol. 116, no. 3, pp. 353-359, 2000.

[28] D. E. Cameron and G. Woods, "s-continuous and s-open mappings," preprint, 1987.

[29] M. Khan and B. Ahmad, "On s-continuous, s-open and sclosed mappings," Punjab University Journal of Mathematics, vol. 34, no. 1, pp. 107-114, 2001.

[30] S. P. Sinha and S. Malakar, "On s-closed fuzzy topological spaces," Journal of Fuzzy Mathematics, vol. 2, no. 1, pp. 95-103, 1994.
[31] P. Pao-Ming and L. Ying-Ming, "Fuzzy topology-II: product and quotient spaces," Journal of Mathematical Analysis and Applications, vol. 77, no. 1, pp. 20-37, 1980. 

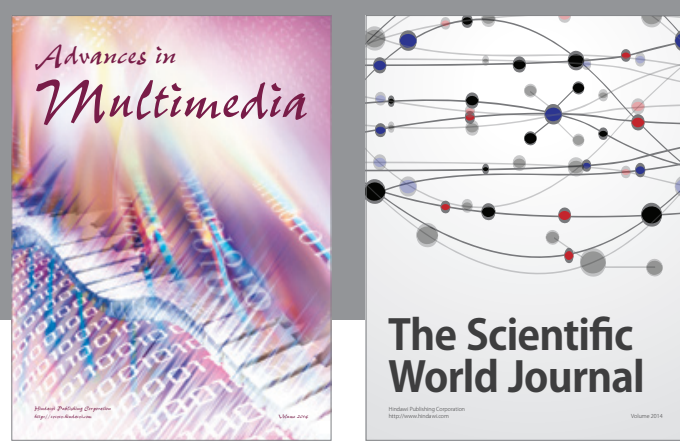

The Scientific World Journal
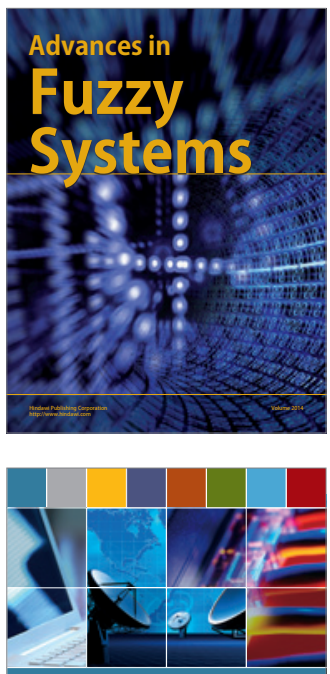

Computer Networks and Communications
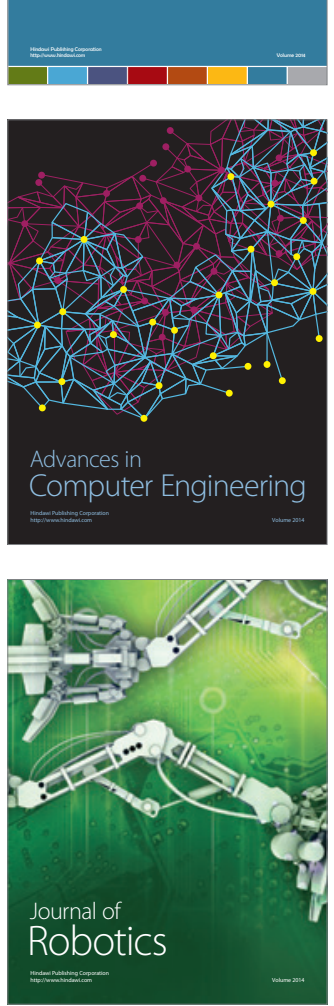
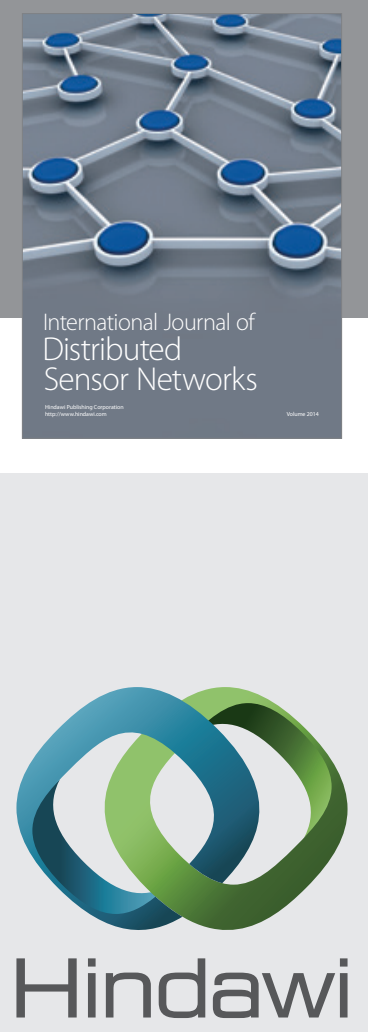

Submit your manuscripts at

http://www.hindawi.com
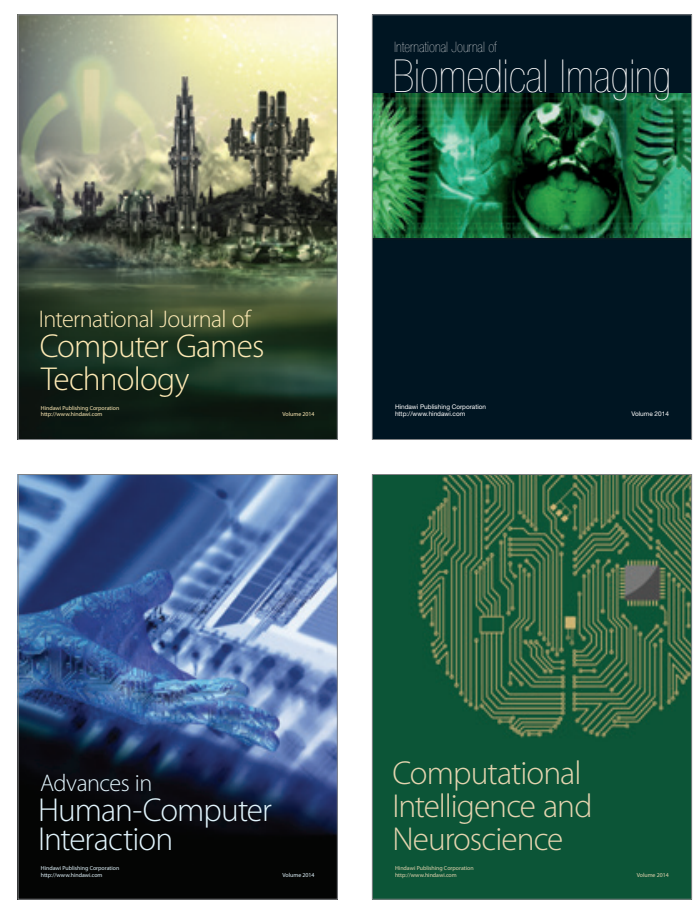
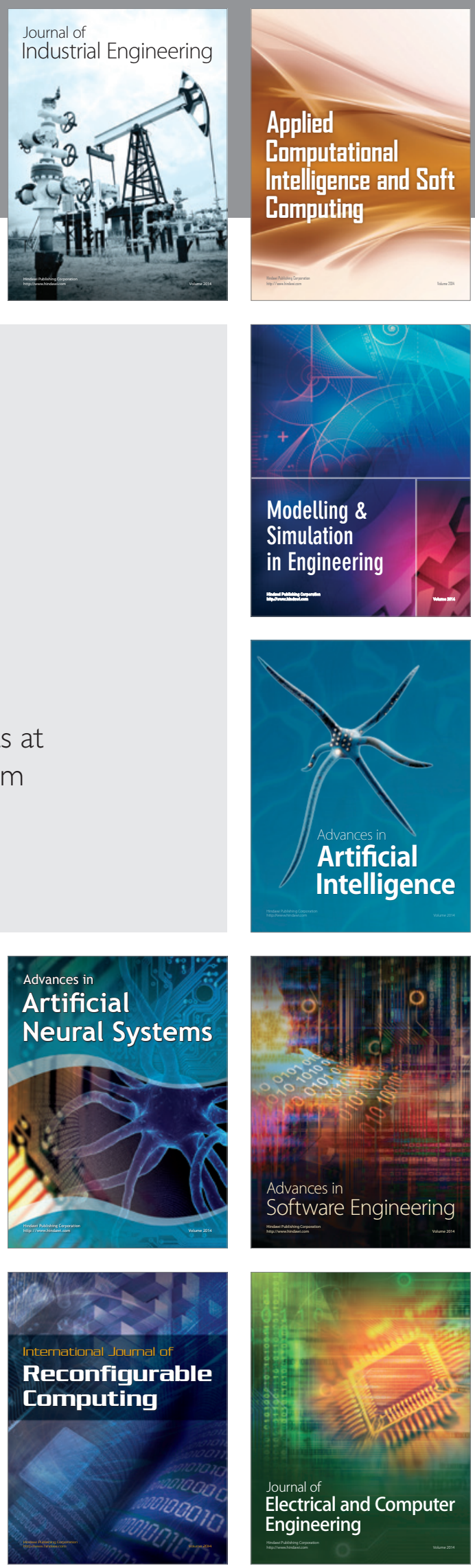